\title{
THE RELATION BETWEEN EEG PREFRONTAL ASYMMETRY AND SUBJECTIVE FEELINGS OF MOOD FOLLOWING 24 HOURS OF SLEEP DEPRIVATION
}

\author{
Camila Ferreira ${ }^{1}$, Andréa Deslandes ${ }^{1}$, Helena Moraes ${ }^{1}$, Maurício Cagy², \\ Luiz Fernando Basile3, Roberto Piedade 4 , Pedro Ribeiro ${ }^{5}$
}

\begin{abstract}
Several studies have investigated the relationship between asymmetrical EEG activity over the f rontal cortex and mood. This study aimed at investigating the association between state fluctuations in frontal alpha EEG asymmetry and state changes followed by $24 \mathrm{~h}$ of sleep deprivation (SD). Our results show that sleep deprivation caused a significant alteration in the asymmetry values. Activation shifted from the left hemisphere, before SD, to the right hemisphere, after SD, in all frontal electrode pairs. In addition, according to the self-rating scale of SD-related mood effects, subjects became significantly less a le rted and active, and sleepier. According to these results, increased right pre frontal activation might be potentially associated with the negative mood states typically seen after sleep deprivation, although the causal relationship is still uncertain. However, more studies will be necessary to establish the viability of EEG asymmetry and the cerebral lateralization hypothesis to explain the SD-related affective changes.
\end{abstract}

KEY WORDS: EEG prefrontal asymmetry, sleep deprivation, affective disorders.

\begin{abstract}
Relação entre assimetria pré-frontal no EEG e sensações subjetivas de humor após $\mathbf{2 4}$ horas de privação de sono

RESUMO - Diversos estudos têm investigado a relação entre a atividade assimétrica do EEG no córtex frontal e mudanças no humor. Adotando tal abordagem, o presente estudo teve como objetivo investigar a associação entre os estados de oscilação na assimetria frontal de alfa e mudanças no estado emocional ou motivacional após $24 \mathrm{~h}$ de privação de sono. Os resultados mostram que $24 \mathrm{~h}$ de privação de sono ocasionaram alterações significativas nos valores de assimetria. Ativação cerebral mudou do hemisfério esquerdo, antes da privação de sono, para o hemisfério direito, após a privação de sono, em todos os pares de eletrodos frontais. Além disso, de acordo com a escala relacionada aos efeitos subjetivos do humor após privação de sono, os sujeitos mostraram-se significativamente menos alerta e ativos e mais sonolentos. É possível que as duas variáveis estejam associadas, embora a relação causal seja ainda incerta. Estudos serão ainda necessários para que se possa estabelecer a viabilidade da assimetria pré-frontal e da hipótese de lateralização cerebral na elucidação de mudanças emocionais relacionadas à privação ou falta de sono.
\end{abstract}

PALAVRAS-CHAVE: assimetria pré-frontal, privação de sono, desordens afetivas.

Over the past years, clinical and laboratory observations suggest that frontal EEG asymmetry reflects individual diff e rences in the regulation of an elicited emotion, a biological marker of affective style ${ }^{1-5}$. According to Petruzzello et al. ${ }^{6}$ EEG frontal asymmetry reflects a diathesis that, in concurrence with an emotion elicitor stimulus, will result in a change in positive or negative affect appropriate with the emotion-eliciting stimulus. Even though such evidence does not involve sleep deprivation (SD), there have been many studies examining EEG activity as a consequence of total or partial sleep deprivation which reported decreased alpha power and concomitant reduced alertness and increased irritability ${ }^{7-9}$.

However, up to now, no investigations have observed the relationship between motivational or mood changes after SD and pre frontal asymmetry. But, given the acknowledged SD-related negative

\footnotetext{
'Laboratório de Mapeamento Cerebral e Integração Sensório-Motora, Instituto de Psiquiatria (IPUB), Universidade Federal do Rio de Janeiro, Brasil (UFRJ); ${ }^{2}$ COPPE, UFRJ; ${ }^{3}$ Laboratório de Neurociências (LIM-27) Faculdade de Medicina da Universidade de São Paulo SP, Brasil; ${ }^{4}$ Coordenador Laboratório de Mapeamento Cerebral e Integração Sensório-Motora, IPUB, UFRJ; ${ }^{5}$ Escola de Educação Física e Desportos (EEFD) - Departamento de Biociências e Atividade Física, Laboratório de Mapeamento Cerebral e Integração Sensório-Motora, IPUB-UFRJ, Professor Pesquisador Universidade Castelo Branco (PROCIMH-UCB).
}

Received 9 September 2005, received in final form 20 February 2006. Accepted 2 March 2006.

Dra. Camila Ferreira - Rua Delfina 47 / 104 - 20511-270 Rio de Janeiro RJ - Brasil. E-mail: camilaferreira@libero.it. 
mood/affective changes $\mathrm{s}^{9-12}$ and according to the cerebral lateralization hypothesis, we may well observe if these variables are correlated, helping to understand how the brain adjusts itself when confronted with sleep loss or sleep deprivation.

The refore, the primary purpose of this study was to observe alterations in EEG pre frontal asymmetry after sleep deprivation; and if SD-related affective changes are associated with such electrophysiological adjustments. We predicted that more activation in the anterior portions of the right hemisphere, relative to the anterior portions of the left hemisphere should occur as a result of sleep deprivation, and that such modifications are related to enhanced negative affect.

\section{METHOD}

Subjects - The sample consisted of 11 individuals, 4 males and 7 females, with ages varying between 21 and 40 years $(30.8 \pm 6.0$ years), weighing between 55 and $92 \mathrm{~kg}$ $(70.5 \pm 17.2 \mathrm{~kg})$. All subjects were healthy, right-handed, non-smokers, free of cognitive deficits and were not making use of oral contraceptives or any psychoactive or psychotrqpic substance at the time of the test. To ensure that subjects did not present any impairment of their physical and mental health, a questionnaire was applied. The questionnairealso aimed at identifying food intake, body temperature, fatigue, and drugs use, among others. Subjects we re not allowed to consume any alco holic beverages or caffeine. The Edinburgh inventory ${ }^{13}$ was used to assess laterality and exclude left-handed individuals from the experiment. All subjects signed a consent form, where the experimental condition was thoroughly described. The Psychiatric Institute's Ethics Committee approved the experiment.

Study design and procedures - The procedures were standardized in two diff e rent times; pre- and post-sleep deprivation, following the subsequent routine: subjects arrived at the laboratory by 8:00 p.m. , performed a baseline eight-minute EEG recording ( 4 minutes with eyes closed and 4 minutes with eyes open) and answered to an 11-item sleep deprivation-related mood changes questionnaire (better described below). An abbreviated form was favored because of the several estimations that were made along which objected a rapidly conclusion, allowing a close time correspondence with EEG measures night. It is relevant to remind that the questionnaire used here attempted to reflect mood changes related only to the sleep deprivation e ffects, re p roducing pleasant (active, energetic, alerted, satisfied) and unpleasant states (sleepy, drowsy, tired, lazy, depressed). Nevertheless, the same elicitor will produce an array of different emotions across subjects ${ }^{14}$, even in response to elicitors that are specifically chosen to target particular emotions. During all night long, volunteers played games, watched videos and carried out recreational activities, and were also fed each three or four hours. Two experimenters were required to ensure continuous wakefulness of the subjects monitored sleep deprivation continuously. Subjects abstained from smoking or drinking xanthine-containing beverages (coffee, tea, cola or soft drinks). No conc u rrent treatment was allowed during the study. At 7:00 a.m. (Time 2- after sleep deprivation) of the subsequent morning, all subjects repeated the same identical EEG recording and answered on more time the mood-related changes questionnaire.

Data acquisition - The study design respected the International Pharmaco-EEG group guidelines. During the task, all lights remained turned off to minimize visual stimuli interferences, besides the video monitor. Individuals sat comfortably in a large supported chair, in order, to also minimize also muscular artifacts inside this sound-light-attenuated room, while EEG was collected from 20 monopolar derivations for eight minutes (eyes closed, alert but resting). Data were collected with eyes closed in order to observe the cortex electrical activity without any external stimuli, minimizing possible visual artifacts. Electrodes were positioned according to the International 10 / 20 System (referred to linked earlobes with ground at FPZ). All elect rode impedances were kept below $5 \mathrm{k} \Omega$. The signal was amplified with a gain of 22,000, analogically filtered between $0.01 \mathrm{~Hz}$ (high-pass) and $100 \mathrm{~Hz}$ (low-pass), and sampled at $240 \mathrm{~Hz}$ using a Braintech-3000 ${ }^{\circledR}$ (EMSA-Medical Instruments, Rio de Janeiro, Brazil) EEG acquisition system. The EEG was recorded by means of the software ERP Acquisition (Delphi $5.0^{\circledR}$, Borland-Inprise), developed at the Brain Mapping and Sensorimotor Integration Lab, employing the following digital filters: notch $(60 \mathrm{~Hz})$, high-pass of $0.3 \mathrm{~Hz}$ and low-pass of $30 \mathrm{~Hz}$. Visual inspection was employed for detection and elimination of artifacts. Eye-movement (EOG) artifact was monitored with a bipolar electrode montage using two 9-mm-diameter electrodes attached superior to and on the external cantus of the right eye.

Data analysis: Alpha asymmetry - EEG containing art ifact was marked and excluded from each EEG trial prior to further analysis of the data. All artifact-freedata extracted from the EEG's total recordwere subjected to a Matlab $5.3^{\circledR}$ (The Mathworks Inc., Massachusetts, USA) routine to perform power spectral analysis, producing estimates of absolute spectral power ( $\mu \mathrm{V} 2)$ and asymmetry for the alpha $f$ requency band. A Fast Fourier Transformation (FFT) was applied, analyzing the repetitive data during regular time intenals. Therefore, through the FFT, it is possible to define how much energy (power) exists in a given frequency band. Afterw a rds, a natural log transformation was applied to power density values to normalize the distribution. Power spectral analysis had to be carried out, in order to extract the asymmetry values. Subjects had a minimum of 25 artifact-fre epochs for each experimental time. After the data acquisition and storage, all statistics were computed to extract the asymmetry values for the alpha frequency band in the frontal areas of the brain cortex (Fp1-Fp2, F3-F4, and F7-F8). Although the software provides us with power spectral data from all electrode sites in the four frequency bands, we have focused our analysis on the three anterior 
electrale pairs, because previous researches ${ }^{2,3,15}$ showed relations between brain electrophysiology at these sites and measures of affective states. In addition, power in the alpha band (typically in the $8-13 \mathrm{~Hz}$ ) is inversely related to activation and has been the measure most consistently obtained in studies ${ }^{14}$ of EEG asymmetry. Alpha power has been found to be more reliably related to task perf ormance compared with power in other frequency bands, when the tasks that are compared are carefully matched on psychometric properties and since it is inversely related to activation, blocking of or decreases in alpha are seen ${ }^{16}$ when underlying cortical systems engage in active processing. Moreover, alpha asymmetry has been found ${ }^{15}$ to be re latively stable over a three-week interval leading ${ }^{1}$ Davidson suggested that this measurement reflects a trait-like tendency to respond diff e rentially to positive (i.e. appro a chrelated) and negative (i.e. withdrawal-related) stimuli. Therefore, we expected that the SD-related affective changes would differ on measures of alpha power asymmetry, especially in anterior regions. The alpha power asymmetry may be considered a gradient of power that exists between the two homologous electrodes in the pair, with the slope of the gradient being towards the electrode with the greatest amount of power in this frequency band. Computational indices of power asymmetry provide a left-right comparison in the alpha frequency band, as well as homologous bipolar pairs and across the specified multivariate electrode arrays (for example, left hemisphere versus right hemisphere power asymmetry). The basic mathematical formula (Matlab $5.3^{\circledR}$ The Mathworks Inc., Massachusetts, USA) for asymmetrycalculations is \% Asymmetry $=(L-R / L+R) \times 100$. Where $L$ refers to the left homologous electrode in the pair of compareelectrodes, and $\mathrm{R}$ is the right homologous electrode.

Self-rating scale of mood effects - This is an 11-item four-point self-rating scale utilized ${ }^{17}$ in sleep deprivationparadigms. Motivational or affective states in this study should be related to sleep deprivation or sleep loss. The most frequent emotions considered in asymmetry studies, such as happy or sad wouldn't make sense in this paradigm. The subjective effects evaluated should be related to the emotion elicitor ${ }^{14}$, although the same elicited produces an a rray of unintended emotions across subjects. For example, when investigating hemispheric activation and exercise-related affective states, Petruzzello ${ }^{18}$ and Landers and Petruzzello et al. ${ }^{6}$ assessed pleasant emotions related to the elicitor, exercise, such as, reduced anxiety or increased energetic arousal. In the present study, individuals reported their subjective state in terms of the eleven clusters of the following effects: alert, satisfied, nervous, sleepy, active, dep ressed, talkative, headache, upset stomach, lazy, irritable.

Statistical analysis - Data were expressed as mean \pm . $d$. The statistical software SPSS for Windows was used for all data analysis. Asymmetry values were submitted to a nonparametric Wilcoxon analysis, in order to observe variations in the hemispheres activation pre and post $24 \mathrm{~h}$ of sleep deprivation. A paired t-test was perf o rmed to compare the questionnaire scores in the two experimental times (preand post-sleep deprivation ). Sleep deprivation effects on asymmetry - related brain activation were examined comparing EEG data collecte d pre sleep deprivation with the first post sleep deprivation measures. Significance levels were set at $\mathrm{p} \leq 0.05$.

\section{RESULTS}

Electrophysiological results - Twenty-four hours of sleep deprivation caused an activation shift from the left hemisphere to the right hemisphere in all frontal and prefrontal electrode pairs analyzed in this study. Statistical analysis comparing all pre and post sleep deprivation asymmetry values showed a significant increase in hemispheric asymmetry. According to the mathematical formula from the software utilized in this study (Matlab 5.3 ${ }^{\circledR}$ The Mathworks Inc., Massachusetts, USA) the preponderance of negative asymmetry values observed after sleep deprivation demonstrates that the activation in the right side of the frontal cortex was greater, therefore, creating the distinctive electrophysiological patterns observed: Asymmetry $=(L-R) / L+R \times 100$. Statistical analysis demonstrated a significant diff e rence in hemispheric asymmetry before and after SD in the three electrode pairs re $p$ resenting the frontal cortex: Fp1 Fp2 $p=0.026$, F3 F4 $p=0.004$ and F7 F8 $p=0.021$. The energy shift in the alpha frequency band from the left hemisphere to the right hemisphere after $24 \mathrm{~h}$ of SD resulted in greater right-side activation (negative asymmetry values), which could be related to

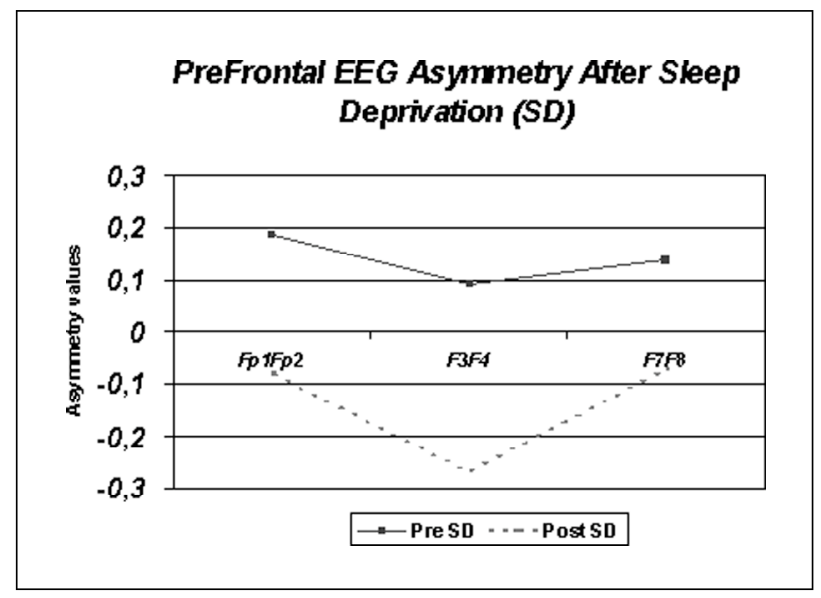

Fig 1. Twenty-four hours of sleep deprivation (SD) caused a shift in hemisferic activation resulting in greater right side activa tion, which is confirmed by the asymmetry negative values (not specifically shown here) observed after SD. Statistical analysis $p$ roduced the following $p$ values $0.026,0.004$ and 0.021 , repre senting electrode pairs Fp1-Fp2, F3-F4 and F7-F8, respectively. $P$ re $S D=$ before sleep deprivation; Post $S D=$ after sleep depriva tion. 
Activation Scale

Low Activation

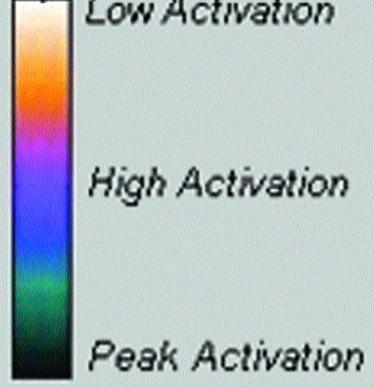

F4 $\mathrm{Fz}$

F4

F3

F8

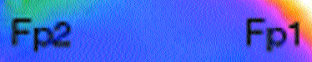

F7

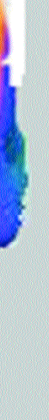

Fig 2. Illustrates sites of lower and higher activations in the alpha range after sleep deprivation. Note that the electrodes from the right hemisphere present greater levels of activation, compared to the electroles from the left side of the pre frontal area. This figure has illustrative purpuses only it does not show any statistical analysis, the image was simple plotted using the before and after asymme try values.

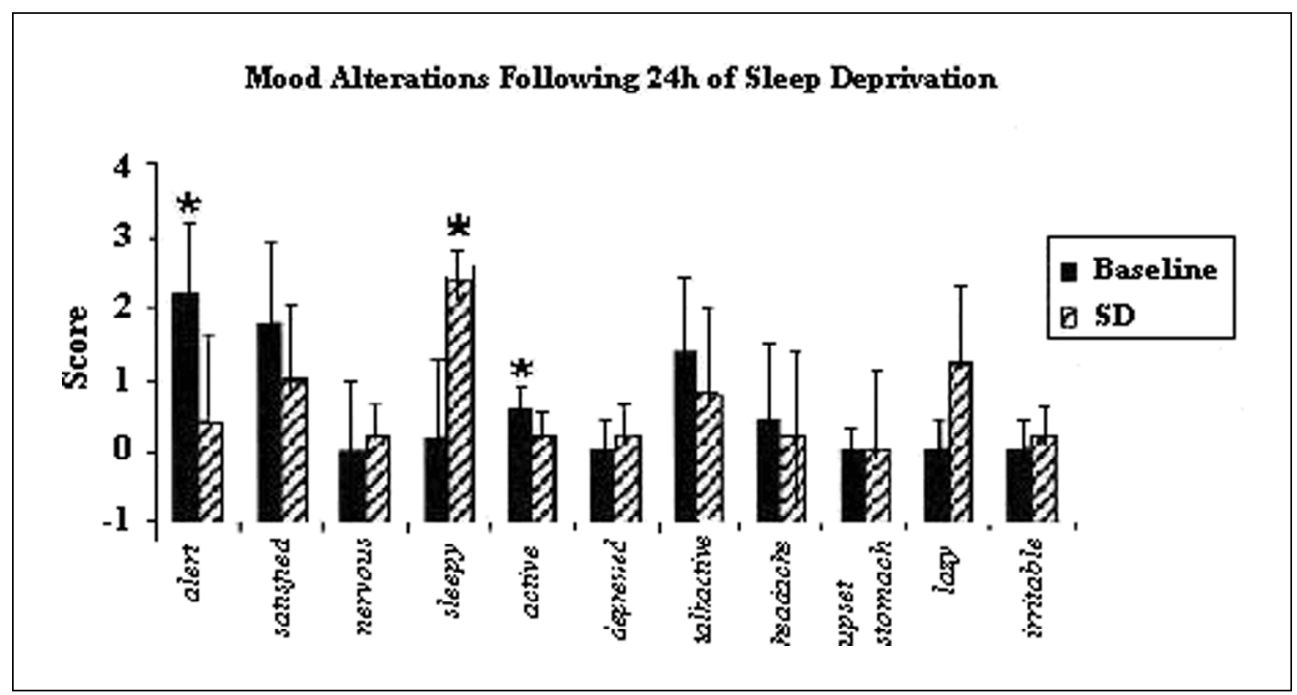

Fig 3. Twenty-four hours of sleep deprivation (SD) resulted in significant withdrawal-related nega tive mood effects. Sleepiness increased while subjects showed decreased active and alertness levels. $P \leq 0.05$.

the negative emotional state often seen after sleep loss $^{9-12}$. Electrophysiological results from the three prefrontal electrode pairs are shown in Figure 1. Figure 2 has illustrative purposes only and re presents sites of greater and lower activation in the frontal cortex after sleep deprivation. It is perceptible that the electrodes from the right frontal hemisphere experienced higher activation following SD.

Subjective evaluation of mood - To observe the effects of sleep deprivation on mood or affective sta- 
tes, a t-test was applied. The statistical analysis examined the following mood/affective changes related to sleep deprivation: alertness, satisfied, sleepy, active, depressive, talkactive, headache, upset stomach, lazy and irritable. After $24 \mathrm{~h}$ of SD subjects became significantly less alerted $(p=0.01)$ and active $(p=0.04)$ and more sleepy $(p=0.001)$. According to Davidson et al. ${ }^{14}$, the subjective effects evaluated should be related to the emotion elicitor, which in this case is the deprivation or lost of sleep, and the emotion elicitor-negative affect or state should be associated with the withdrawal system. The significant effects of sleep deprivation on affective states are demonstrated in Figure 3.

\section{DISCUSSION}

Total or partial sleep deprivation causes significant perf o rmance impairment throughout different cognitive and psychomotor tasks and is also related to reductions in alertness, sustained and selective attention levels $\mathbf{s}^{7,9-11}$. Besides cognitive deterioration, SD is also followed ${ }^{9,10}$ by changes in mood or emotional states, often resulting in negative affective states. Therefore the primary purpose of this study was to observe the cerebral lateralization hypothesis during an investigational test. In addition, we tried to evaluate if post SD-related negativeaffective/mood changes are associated with increased right prefrontal hemisphere activation. According to Petruzzello et al. 6 , an emotion elicitor stimulus of sufficient intensity, will result in a change in positive or negative affect, which is associated with EEG frontal asymmetry. Following Davidson's ${ }^{1,4}$ approach-withdrawal model and taking SD as an emotion elicitor, we predicted that post SD-related negative affective changes would be associated with an EEG state frontal asymmetry, specifically, a greater right frontal hemisphere activation in the alpha frequency band. In this study, the alpha band (typically in the $8-13 \mathrm{~Hz}$ ) has been chosen as an electrophysiological marker because, as quoted before, it is relatively stable ${ }^{14,15}$ and inversely related to activation. Hence, it has been the measure most consistently obtained in studies of EEG asymmetry, leading ${ }^{1,4,5}$ Davidson to suggest that this measu rement reflects a trait-like tendency to respond differentially to positive (i.e. approach-related) and negative (i.e. withdrawal-related) stimuli. Furthermore, EEG power spectra studies have generally reported a decrease in alpha power (increased activation) after SD, which could account for the negative mood variations frequently observed ${ }^{12,19}$ following sleep loss or sleep deprivation. Since influent previous investi- gations demonstrated a relationship between brain electrophysiology in prefrontal area and measures of affective states ${ }^{1-4,20}$, we have also focused our analysis on the three anterior electrode pairs, Fp1-Fp2, F3-F4, F7-F8.

The results demonstrated that $24 \mathrm{~h}$ of SD caused significant changes in EEG asymmetry, producing an activation shift from the left hemisphere to the right hemisphere in all anterior electrodes pairs, which is represented by the negative asymmetry values in the post SD time. SD-related mood variations extracted from the self-report mood scale in the two experimental times reported a significant increase in sleepiness and reduction in active and alertness levels. The association between the contextual negative emotional states observed after sleep deprivation and the increased right frontal activation in the alpha band might be related to Davidson's withdrawal hypothesis ${ }^{20}$ and could partially explain the negative effects often seen after sleep loss. According to Davidson, the right prefrontal cortex is a biological substrate of the withdrawal behavior, inhibition and negative emotional states, mediating also attention and alertness (toward the stimulus). Our results demonstrate a likely association between negative emotional states, particularly elicited by sleep deprivation, and increased right prefrontal activation, although it is not entirely clear if prefrontal asymmetry plays a causal role in the outcome measures. In other words, it is still unsure if the shift in hemispheric activation seen after sleep deprivation produced the negative motivational or mood effects or if it is the contrary. Hence, the small sample presented here could have influenced our results. It is, therefore, essential to continue other investigations using a larger number of individuals. It is relevant to remind that the present study did not attempt to examine if EEG asymmetry measured during resting conditions (trait fro $n$ tal asymmetry) could predict such affective responses to the emotion elicitor (sleep deprivation). Instead, it has followed a different research approach where EEG asymmetries (state frontal EEG asymmetry) may be thought of as those that are responsive to specific environmental conditions.

In conclusion, it appears from the present findings that changes in brain activation, characterized by increased right prefrontal activation, might at least partially explain the negative mood states typically seen after sleep deprivation, and therefore, the theory of individual diff e rences in response to this specific emotion elicitor may be hypothesized. In ad- 
dition to replicating the present findings, future work also needs to examine SD-related affective responses of subjects with: 1) previously higher levels of negative affect, 2) suffering from mood or anxiety diso rders and 3) resting EEG asymmetry as a predictor of emotional responses to sleep deprivation or sleep loss. Measuring the differences in individual response to SD-mood effects might be interesting and useful, given the involvement of almost all psychopathologies in the sleep regulation.

\section{REFERENCES}

1. Davidson RJ. Anterior cerebral asymmetry and the nature of emotion. Brain Cognit 1992; 20:125-151.

2. Harmon-Jones E, Allen JJ. Behavioral activation sensitivity and resting f rontal EEG asymmetry: covariation of putative indicators related to risk for mood disorders. J Abnormal Psychol 1997;106:159-163.

3. Sutton KS, Davidson RJ. Prefrontal brain electrical asymmetry predicts the evaluation of affective stimuli. Neuropsychologia 2000;38:17231733.

4. Davidson RJ. Asymmetric brain function, affective style and psychopathology: the role of early experience and plasticity. Develop Psychopathol 1994;6:741-758.

5. Sackeim HA, Greenberg MS, Weiman AL, Gur RC, Hungerbuhler JP, Geschwind N. Hemispheric asymmetry in the expression of positive and negative emotions: neurological evidence. Arch Neurol 1982; 39:210218.

6. Petruzzello SJ, Hall E, Ekkekakis P. Regional brain activation as a biological marker of affective responsivity to acute exercise: influence of fitness. Psychophysiology 2001;38:99-106.

7. Corsi-Cabrera M, Arce C, Ramos J, Lorenzo I, Guevara MA. Time course of reaction time and EEG while performing a vigilance task during total sleep deprivation. Sleep 1996;19:563-569.
8. Cajochen C, Foy R, Dijk DJ. Frontal predominance of a relative increase in sleep delta and theta EEG activity after sleep loss in humans. Sleep Res Online 1999; 2:65-69.

9. Babkoff H, Caspy T, Mikulincer M. Subjective sleepiness ratings: the effects of sleep deprivation, circadian rhythmicity and cognitive performance. Sleep 1991;14:534-539.

10. Batejat D, Lagarde D. Circadian rhythm and sleep deprivation: effects on psychomotor performance. Med Sci Res 1992;20:167-168.

11. Dinges DF. An overview of sleepiness and accidents. J Sleep Res 1995;4:4.

12. Dijkman M, Sachs N, Levine E et al. Effects of reduced stimulation on ne u robehavioral alertness depend on circadian phase during human sleep deprivation. Sleep Res 1997;26:265.

13. Jung $P$, Baumgärtner $U$, Bauermann $T$, et al. Asymmetry in the human primary somatosensory cortex and handedness. Neuroimage 2003; 19:913-923.

14. Davidson RJ, Ekman P, Saron CD, Senulis JA, Friesen WV. Approachwithdrawal and cerebral asymmetry: emotional expression and brain physiology I. J Pers Soc Psycho 1990; 58:330-341.

15. Tomarken AJ, Davidson RJ, Wheeler RE, Doss RC. Psychometric properties of resting anterior EEG asymmetry: temporal stability and internal consistency. Psychophysiology 1992;29:576-592.

16. Davidson RJ, Chapman JP, Chapman LJ, Henriques JB. Asymmetrical brain electrical activity discriminates between psychometricallymatched verbal and spatial cognitive tasks. Psychophysiology 1990; 27:528-543.

17. James JE, Gregg ME. Hemodynamic effects of dietary caffeine sleep restriction, and laboratory stress. Psychophysiology 2004;41:914-923.

18. Petruzzello SJ, Landers DM. State anxiety reduction and exercise: does hemispheric activation reflect such changes? Med Sci Sports Exercise 1994;26:1028-1035.

19. Corsi-Cabrera M, Sanchéz AI, Del-Rio-Portilla Y, Villanueva Y, PérezGarcí. Effect of $38 \mathrm{~h}$ of sleep deprivation on the waking EEG in women: sex differences. Int Psychophysiol 2003;50:213-224.

20. Davidson RJ, Irwin W. The functional neuroanatomy of emotion and affective style. Trends Cogn Sci 1991;3:11-21. 